\title{
Macroeconomic Policy in a Two-party System as a Repeated Game
}

\section{Citation}

Alesina, Alberto. 1987. Macroeconomic policy in a two-party system as a repeated game. Quarterly Journal of Economics 102(3): 651-678.

\section{Published Version}

http://dx.doi.org/10.2307/1884222

\section{Permanent link}

http://nrs.harvard.edu/urn-3:HUL.InstRepos:4552531

\section{Terms of Use}

This article was downloaded from Harvard University's DASH repository, and is made available under the terms and conditions applicable to Other Posted Material, as set forth at http:// nrs.harvard.edu/urn-3:HUL.InstRepos:dash.current.terms-of-use\#LAA

\section{Share Your Story}

The Harvard community has made this article openly available.

Please share how this access benefits you. Submit a story.

Accessibility 


\title{
MACROECONOMIC POLICY IN A TWO-PARTY SYSTEM AS A REPEATED GAME*
}

\author{
Alberto Alesina
}

\begin{abstract}
This paper considers the interaction of two parties with different objectives concerning inflation and unemployment and rational and forward-looking wagesetters. If discretionary policies are followed, an economic cycle related to the political cycle results in equilibrium. This cycle is significantly different from the traditional "political business cycle." Reputational mechanisms due to the repeated interaction of the two parties and the public or commitments to a common policy rule can improve upon the discretionary outcome by reducing or eliminating the magnitude of the economic fluctuations.
\end{abstract}

\section{INTRODUCTION}

Two different approaches can be taken in modeling the relationship between the political system and macroeconomic policy. At one extreme it can be assumed, following Downs [1957], that the sole objective of political parties is to remain in office. They do not care about the effects of their policies on the economy except insofar as they influence voters' electoral choices. This assumption produces the result that, for a given voting function and structure of the economy, in a two-party system both parties propose the same platform to the voters and implement the same policies if elected. This result holds even if the parties are uncertain about voters' preferences as long as they share the same information about voters' tastes. The most important macroeconomic application of this approach is probably the "political business cycle" of Nordhaus [1975] and McRae [1977].

The second approach, much less developed in the literature, is to assume that different parties have different preferences concerning the intrinsic properties of their economic policies, for example, because each party represents the interests of a different constituency. In this case, if there is uncertainty about voters' preferences, the two parties propose different platforms even if they share the

*This paper is based on one chapter of my Ph.D. dissertation at Harvard University [May 1986]. I am greatly indebted to Jeffrey Sachs for having directed my attention toward these issues and for many helpful conversations and suggestions. I also benefited from conversations with Andrew Abel, Dilip Abreu, Olivier Blanchard, Ramon Caminal, Andrew Caplin, Morris Fiorina, Benjamin Friedman, Herschel Grossman, Maria Herrero, Howard Rosenthal, and Susan Vitka. The comments of a referee greatly improved the paper. Ente "Luigi Einaudi" provided generous financial support. The views expressed in the paper are mine, as is the responsibility for any mistakes. 
same information about the distribution of voters' preferences. ${ }^{1}$ Thus, different parties are modeled as policymakers with different objective functions. The parties gain access to policymaking via elections with uncertain results.

This paper adopts the second approach: it is assumed that parties care about the inherent effects of their policies and that parties have different objectives and incentives. ${ }^{2}$ Which of the two assumptions about parties' behavior is closer to the truth is an empirical question, the answer to which may vary across countries and time periods. The "political business cycle" approach has received weak support from United States data. ${ }^{3}$ On the contrary, a partisan view of macroeconomic policy implying that different parties act differently when in office has received increasing support both for the United States and for other industrialized economies. In particular, empirical arguments have been made that leftist parties in Europe and the Democratic party in the United States have been relatively more averse to unemployment and less averse to inflation than conservative parties in Europe and the Republican party in the United States. ${ }^{4}$

The existence of two different policymakers that alternate in office raises important questions concerning the credibility and dynamic consistency of policy announcements. This paper analyzes the interaction of two parties with different policy goals and rational forward-looking wage-setters in a game-theoretic model close to that proposed first by Kydland-Prescott [1977] and extended by Barro-Gordon [1983]. In that game the private agents (or wage-setters) act first by setting the nominal wage. The policymaker acts second. He has an incentive to announce a policy of low inflation, but then would like to generate unexpected inflation in order to reduce unemployment. Since the wage-setters are rational and informed, they recognize this incentive and set the nominal

1. This result is proved in a context similar to that of this paper by Alesina [1986], who extends earlier results by Calvert [1985] and Wittman [1977, 1983].

2. Blanchard [1985] has followed the same approach. In a somewhat different setting, a similar approach is adopted by Minford-Peel [1982].

3. Nordhaus [1975] presents empirical evidence for the United States favorable to his approach. Subsequent papers, for example, McCallum [1978], Golden-Poterba [1980], and several others, have rejected the "political business cycle" theory for the United States.

4. Hibbs [1977] was the first to point out this empirical regularity and recently reinforces his point [forthcoming]. Similar findings have been presented by Beck [1982, 1984], Havrilesky [forthcoming], Tabellini-La Via [1986], and Alesina-Sachs [forthcoming]. Poole-Rosenthal [1986] have shown that in general there is polarization in American politics concerning economic policy. 
wage high enough to eliminate any incentive for the policymaker to generate surprise inflation. If binding commitments are unavailable, the result of this game is in general inefficient, even though reputational forces may mitigate the magnitude of the problem, as Barro-Gordon [1983] first pointed out. In equilibrium, employment cannot be affected by the policymaker and inflation is higher than optimal. The model implies complete policy neutrality and an inflationary bias. ${ }^{5}$

The present paper analyzes a similar game in the context of a two-party system. The two parties assign different weights to unemployment and inflation as economic "bads." In particular, the parties differ in two crucial respects: their optimal policies are different, as are their incentives to generate policy surprises. Thus, the two parties want to commit to different policy rules and have different incentives to deviate from their commitments.

The present paper shows that if the two parties are shortsighted, fluctuations in output and inflation connected with the political cycle result in equilibrium. This economic cycle, however, is quite different from the conventional "political business cycle" à la Nordhaus and does not rely on irrational voting behavior, irrational expectations, or misinformation of voters. It is shown that costly economic fluctuations can be avoided if the parties recognize that the adoption of a cooperative common policy rule makes both constituencies better off in the long run. Thus, when a party is elected, it faces a choice: it can follow a policy that will maximize short-run benefits for its constituency, or it can follow the cooperative policy that makes both constituencies better off in the long run. If binding commitments are available, the two parties should bind themselves to the cooperative rule. Thus, this paper provides an additional argument in favor of rules rather than discretion. ${ }^{6}$

Even if binding commitments are unavailable, reputational forces arising from the repeated interaction of the two parties can improve upon the discretionary outcome. The first best policy may or may not be sustainable through reputational effects, depending on several characteristics of the economic and political system.

5. A rapidly growing body of research has explored in depth this model. Excellent surveys of this literature are Cukierman [1986], Fischer [1986], and Rogoff
[1987].

6. The issue of stabilization policy in the presence of unforeseen shocks is not considered in this paper. Rogoff [1985] explores the relationship between the benefits of binding commitments to policy rules and the need of flexibility for stabilization purposes. 
The paper also suggests rather precise empirical implications for the United States; a model based on similar ideas has been successfully tested by Alesina-Sachs [forthcoming].

This paper is organized as follows. Section II presents the model. In Section III the discretionary equilibrium is characterized. In Section IV the efficient frontier of the repeated game is obtained. Sections V and VI address the problem of finding the best subgame perfect policies. Section VII briefly extends the results to multiperiod administrations. The main results of the paper are summarized in the concluding section.

\section{THE MODEL}

The economy is characterized by a standard supply function without capital, expressed for convenience in rate of growth:

$$
\left.\dot{y}_{t}=\gamma \Pi_{t}-w_{t}\right)+\bar{y} ; \quad \gamma>0,
$$

where $y_{t}$ is the rate of growth of output; $\Pi_{t}$ is the inflation rate; $w_{t}$ is the rate of growth of nominal wages; and $\bar{y}$ indicates the rate of growth of output compatible with the natural rate of unemployment and has to be interpreted as the rate of growth prevailing in the absence of policy intervention that changes the real wage.

The private agents may be viewed as uncoordinated wagesetters who set the nominal wage. They attempt to keep the real wage constant at the level compatible with the "natural" rate of growth $(\bar{y})$. Wage contracts last one period and are signed at the end of, say, period $(t-1)$ for period $t$. These contracts are not contingent on the state of the world; in particular, full indexation is excluded. ${ }^{7}$ Therefore, wage-setters set the nominal wage growth equal to expected inflation:

$$
w_{t}=\Pi_{t}^{e}=E\left(\Pi_{t} \mid I_{t-1}\right) .
$$

The rate of growth of nominal wage is equal to the rational expectation of inflation formed on the basis of the information set available at time $(t-1)$ (i.e., $\left.E\left(\Pi_{t} \mid I_{t-1}\right)\right)$. Thus, the term "expect" can be used interchangeably with the term "set the nominal wage at."

Substituting (2) into (1) yields

$$
y_{t}=\gamma\left(\Pi_{t}-\Pi_{t}^{e}\right)+\bar{y} .
$$

There are two parties in this economy: party $D$ and party $R$. They differ in two respects. First, although they agree that inflation

7. None of the qualitative results of this paper would change if partial indexation were allowed. 
above a certain level is a "bad," party $D$ is more sensitive than party $R$ to the cost of unemployment. Therefore, party $D$ has a stronger incentive than party $R$ to generate unexpected inflation to promote growth. The policymakers may judge the rate of unemployment determined by the market to be too high because of distortions in the labor market. ${ }^{8}$ Second, apart from considerations about unemployment, the two parties disagree about the level of the optimal inflation rate. Party $D$ believes in higher government spending (for example, to promote welfare programs) and is willing to use money creation as a way of financing it: this implies that the optimal rate of inflation is higher for this party.

The simplest way to characterize the objectives of the two parties is to assume the following cost functions for party $D\left(Z^{D}\right)$ and party $R\left(Z^{R}\right)$ :

$$
\begin{aligned}
Z^{D}= & \sum_{t=0}^{\infty} q^{t} z_{t}^{D}=\sum_{t=0}^{\infty} q^{t}\left[\frac{1}{2}\left(\Pi_{t}-c\right)^{2}-b^{\prime} y_{t}\right], \\
& c>0 ; \quad b^{\prime}>0 ; \quad 0<q<1 ; \\
Z^{R}= & \sum_{t=0}^{\infty} q^{t} z_{t}^{R}=\sum_{t=0}^{\infty} q^{t}\left[\frac{1}{2} \Pi_{t}^{2}\right] .
\end{aligned}
$$

In (4) and (5) $q$ is the discount factor, identical for the two parties. In (4) output growth enters linearly and not quadratically. This greatly simplifies the algebra, leaving the results qualitatively unchanged. The positive parameter $c$ represents the optimal inflation rate for party $D$, regardless of whether or not this inflation is expected. For simplicity and without loss of generality, it is assumed that party $R$ does not attribute any value to unexpected inflation, and that the optimal level of inflation for this party is zero. By substituting (3) into (4), assuming that $\bar{y}=0$ for simplicity), one gets

$$
Z^{D}=\sum_{t=0}^{\infty} q^{t} z_{t}^{D}=\sum_{t=0}^{\infty} q^{t}\left[\frac{1}{2} \Pi_{t}^{2}-b\left(\Pi_{t}-\Pi_{t}^{3}\right)-c \Pi_{t}\right],
$$

where

$$
\begin{aligned}
b & \equiv b^{\prime} \gamma \\
Z^{D} & \equiv Z^{D}-\frac{1}{2} c^{2} /(1-q) .
\end{aligned}
$$

8. These distortions may be due to taxes (as emphasized, for example, by Barro-Gordon [1983]), or monopolistic unions that keep the real wage "too high" to maximize the welfare of union members (as emphasized, for example, by Tabellini [1985] and Driffil [1985]). Alesina-Tabellini [forthcoming] discuss the connection between these two distortions. 
The cost functions (5) and (6) can also be interpreted as the reduced forms of a different model. Suppose that the economy is characterized not by a Lucas supply function such as (3) but by an exploitable tradeoff between inflation and unemployment so that "expected policy matters." A model with a standard Phillips curve can be reduced to a form identical to (5) and (6) even abstracting from considerations about the inflation tax. The reason is that in such a model the optimal inflation rate for the two parties would be different if they pick different points on the exploitable tradeoff. Consider a simple Phillips curve such as

$$
y_{t}=\Pi_{t}-\lambda \Pi_{t}^{\mathrm{e}},
$$

where $0<\lambda<1$. Then, even if $c=0$ in (4), substituting (7) into (4), it follows that

$$
\tilde{Z}^{D}=\sum_{t=0}^{\infty} q^{t}\left[\frac{1}{2} \Pi_{t}^{2}-b\left(\Pi_{t}-\Pi_{t}^{e}\right)-b(1-\lambda) \Pi_{t}^{e}\right] .
$$

Equation (8) essentially is equivalent to (6) for the purpose of this paper. The crucial characteristics of the game are in fact the same using either specification: the optimal inflation rates for the two parties are different, and the time-consistent rate of inflation is higher than the optimal rate for party $D$. The analysis of this paper could also be applied to models with overlapping labor contracts lasting more than one period [Fischer, 1977; Taylor, 1980] or with sticky prices. These models, however, would be more difficult to analyze in this game-theoretic framework because one would have to consider in period $t$ expectations formed in periods $(t-1)$, $(t-2)$, etc.

The model will be solved with (5) and (6), using the first interpretation based on the Lucas supply function (3). It is important to stress that this specification of the model implies complete policy neutrality in a standard one-party system.

It is assumed that the policymaker can control inflation directly. For the purpose of this paper, nothing would be gained by assuming that the party in office can control money creation if the model is then closed by a quantity equation. No distinction is made between the central bank and the government: the assumption is that the party in office has control over monetary policy. ${ }^{9}$

9. The Federal Reserve is certainly not completely independent from the Administration. Havrilesky [1986] has recently stressed this point and surveyed some of the literature on the subject. Weintraub [1978] also raises serious doubts about the independence of the Fed. 
Elections take place at discrete intervals of $N$ periods, with $N$ given exogenously. Elections are held at the beginning of the period. The elected party chooses its policy-the inflation rate-immediately after the election for the same period. The probability distribution of electoral outcomes is taken as exogenous and "common knowledge": party $D$ is elected with probability $P$; and party $R$ with probability $(1-P)$. This assumption is adopted for simplicity in order to abstract from issues related to voting. Alesina [1986] shows how this assumption can be relaxed without altering any of the qualitative features of the results presented in this paper as long as voters are rational, forward-looking, and informed about the objectives of the two parties. The crucial assumption is that there is uncertainty about the distribution of voters' preferences. Thus, for given expected policies, the result of the elections is uncertain.

\section{DiscRETIONARY EQUILIBRIUM}

In a discretionary regime the policymaker minimizes his costs, taking as given the current and future actions of the public and his own future moves. This corresponds to the "one-shot" Nash equilibrium for this game. The timing is as follows. If $t$ is an election year, polls are taken in period $(t-1)$. They reveal that party $D$ will win with probability $P$ and party $R$ with probability $(1-P)$. Once the polls are taken, wage contracts are signed for period $t$. At the beginning of period $t$, elections are held, and immediately after elections the elected party chooses $\Pi_{t}$.

It is easy to show the following (the superscripts $D$ and $R$ indicate the party):

Proposition 1. The one-shot Nash equilibrium (discretion) is given by

$$
\begin{array}{rlrl}
\hat{\Pi}_{t}^{D} & =b+c \quad \forall t ; & & \\
\hat{\Pi}_{t}^{R} & =0 \quad \forall t ; & & \\
w_{t+k N} & =\Pi_{t+k N}^{e}=P(b+c) & & \text { if } t \text { is an electoral year; } k: 0,1, \ldots ; \\
w_{t+i+k N} & =\Pi_{t+i+k N}^{e}=b+c & & i=1, \ldots, N-1 \\
& & & \text { if } D \text { is elected at time } t+k N ; \\
w_{t+i+k N} & =\Pi_{t+i+k N}^{e}=0 & & i=1, \ldots, N-1 \\
& & \text { if } R \text { is elected at time } t+k N .
\end{array}
$$

Proof. If party $D$ is elected at time $t$, in every period it solves

$$
\min _{\Pi_{t}}\left[\frac{1}{2} \Pi_{t}^{2}-b\left(\Pi_{t}-\Pi_{t}^{e}\right)-c \Pi_{t}\right],
$$


taking $\Pi_{t}^{e}$ as given. Solving (9) yields

$$
\Pi_{t}^{D}=b+c .
$$

The analogous problem is solved by Party $R$; the result is $\Pi^{R}=0$. If $t$ is an electoral year, the wage-setters set

$$
w_{t}=\Pi_{t}^{e}=P E\left(\Pi_{t}^{D}\right)+(1-P) E\left(\Pi_{t}^{R}\right)=P(b+c) .
$$

In a non-electoral year, wage-setters have perfect foresight, as there are no electoral surprises. sition.

Several empirical implications can be derived from this Propo-

$$
\text { Q.E.D. }
$$

(i) In the first period of a $D$ administration, there is "unexpected inflation" and output growth above the natural level (i.e., zero). In fact, from Proposition 1, using (3), one obtains

$y_{t}^{D}=\gamma(1-P)(b+c), \quad$ if $D$ is elected at time $t$.

If party $R$ is elected, there is a recession. In fact, using (3), it follows that

$$
y_{t}^{R}=-\gamma P(b+c), \quad \text { if } R \text { is elected at time } t .
$$

In the remaining $(N-1)$ period(s) of both administrations, there cannot be any policy surprises, so output growth is at its natural level.

(ii) The amplitude of these deviations of output growth from zero is positively correlated with the distance between the points of view of the two parties. In fact, the more different are the optimal rates of inflation for the two parties ( $c$ and zero) and the more different their incentives to generate policy surprises ( $b$ and zero), the bigger are the deviations of output growth from zero (ceteris paribus). Thus, the model implies that the more polarized is the political system, the wider are the economic fluctuations.

(iii) The lower (higher) is $P$, the higher (lower) is the output growth determined by party $D$ if elected and the smaller (bigger) is the recession determined by party $R$. In fact, the less expected is the policy implemented by the elected party, the stronger are the real effects of that policy.

(iv) Inflation is always higher during a $D$ administration than 
during an $R$ administration for two reasons: the optimal inflation rate is higher for party $D$ and this party has a stronger incentive to generate surprises; thus, the timeconsistent rate of inflation is higher than the optimal rate for this party. ${ }^{10}$

It is worth emphasizing that none of the implications above would change qualitatively had we assumed that $c=0$; i.e., if we had assumed that the parties have the same optimal policy. For all of the results above to hold, it is necessary and sufficient that the time-consistent policies of the two parties are different. A difference in the time-consistent policies may or may not imply a difference in the optimal policies.

The costs of the discretionary regime as perceived by party $D$ before the elections of time $t$ are, in each period,

$$
\hat{z}_{t}^{D}=\frac{1}{2} P\left(b^{2}-c^{2}\right) .
$$

For party $R$, the same costs are

$$
\hat{z}_{t}^{R}=\frac{1}{2} P(b+c)^{2} .
$$

The costs for party $R$ are increasing with $P$, the probability that this party loses the election. The costs for party $D$ are decreasing with $P$ if and only if $b<c$. If $b$ is "too high," the inflationary bias introduced by party $D$ due to its incentive to generate unexpected inflation is so strong that party $D$ itself would prefer to reduce its likelihood of being elected, in order to reduce this inefficiency.

\section{THe EFFicient FrontieR}

For expositional purposes, let us consider first the case in which $N=1$; i.e., there are elections every period. In this case every period is exactly alike. The more general case will be discussed in Section VII. The efficient frontier of the game can be found by solving, in each period,

$$
\begin{aligned}
\min _{\Pi_{t}^{D}, \Pi_{t}^{R}} P\left[\frac{1}{2} \Pi_{t}^{D^{2}}\right. & \left.-b\left(\Pi_{t}^{D}-\Pi_{t}^{e}\right)-c \Pi_{t}^{D}\right] \\
& +(1-P)\left[\frac{1}{2} \Pi_{t}^{R^{2}}-b\left(\Pi_{t}^{R}-\Pi_{t}^{e}\right)-c \Pi_{t}^{R}\right] \\
& +\theta\left[P \frac{1}{2} \Pi_{t}^{D^{2}}+(1-P) \frac{1}{2} \Pi_{t}^{R^{2}}\right] .
\end{aligned}
$$

10. The rate of inflation generated by party $D$ is constant for the entire term in office. This is due to the fact that output enters linearly in the objective function of this party. Had we assumed a quadratic objective function in output, the inflation in the first period of a $D$ administration would be lower than the inflation in the remaining $(N-1)$ period(s). More details on this case can be found in Alesina [1985]. 
In (16) $\theta$ is the relative weight attributed to party $R$ 's cost. Furthermore, we are interested in the portion of the efficient frontier in which both parties are better off than in the one-shot Nash equilibrium. Thus, we want to impose the following constraints of individual rationality:

$$
\begin{aligned}
& z_{t}^{D} \leq \hat{z}_{t}^{D}, \\
& z_{t}^{R} \leq \hat{z}_{t}^{R} .
\end{aligned}
$$

The solution of this problem yields the following proposition.

Proposition 2. The efficient frontier of the game is given by

$$
\Pi_{t}^{D}=\Pi_{t}^{R}=\Pi_{t}^{e}=\frac{c}{1+\theta} \quad \forall t,
$$

where $\theta>0$ and $\theta(P) \leq \theta \leq \bar{\theta}(P)$.

The two bounds of individual rationality $(\theta$ and $\bar{\theta})$ can be found by imposing (17) and (18).

The "folk theorem" of repeated games assures that, for $q$ sufficiently close to 1 , any individually rational point on the efficient frontier can be sustained as a subgame perfect equilibrium. Therefore, sufficiently farsighted parties can completely avoid macroeconomic fluctuations by choosing a policy intermediate between the two individually most preferred policies. This result is due to the convexity of the cost functions of the two parties: an identical policy rule followed by both parties and thus obtained with certainty, irrespective of the party in office, makes both parties better off than the expected value of the two noncooperative policies weighted by the probability distribution of electoral outcomes.

By substituting the result of Proposition 2 into the cost functions of the two parties, one obtains the efficient frontier in cost space as

$$
z^{D}=z^{R}-c \sqrt{2 z^{R}} .
$$

This curve is represented in Figure I, where $N$ is the one-shot Nash point and the segment between $A$ and $B$ of the curve is the set of individually rational points on the efficient frontier. Different choices of $\theta$ can be identified with different points on the efficient frontier of Figure I. For example, the higher is $\theta$, the closer is the policy chosen to the optimal policy of party $R$ and vice versa.

The choice of $\theta$ can be interpreted as a bargaining problem between the two parties. It would be desirable for the resolution of 


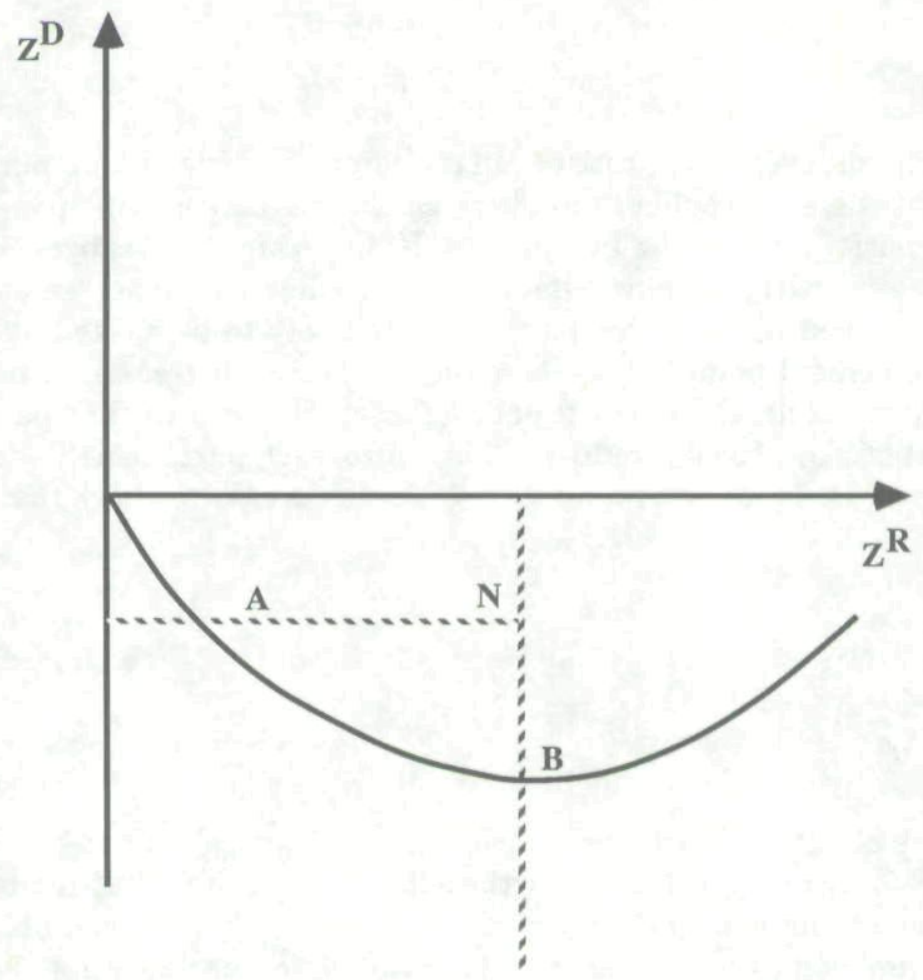

Figure I

this problem to be related to the relative popularity of the two parties. In other words, the lower is $P$, the higher should be $\theta$, the relative weight attributed to party $R$. The Nash bargaining solution has precisely this implication. This solution is based on the assumption that the two parties know that if an agreement is not reached, each party would follow its individually most-preferred policy. These policies characterize the "disagreement point." The following proposition, proved in the Appendix, characterizes this solution.

Proposition 3. If $\theta^{*}$ is the Nash bargaining solution of the game, then the following holds:

$$
\theta^{*} \text { is a function only of } P: \theta^{*}(P) \text {; }
$$

$$
\frac{\partial \theta^{*}}{\partial P}<0
$$




$$
\begin{gathered}
\theta^{*}\left(\frac{1}{2}\right)=1 ; \\
\lim _{P \rightarrow 0} \theta^{*}(P)=\infty ; \lim _{P \rightarrow 1} \theta^{*}(P)=0 .
\end{gathered}
$$

Thus, even in the case of full cooperation in which both parties adopt the same policy, the chosen policy is dependent upon the popularity level of the two parties. If, for example, $P$ exogenously increases, party $D$ knows that its costs are lower if an agreement is not reached because this party is more likely to be elected at the disagreement point. ${ }^{11}$ This increases the bargaining power of party $D$. As a result, the optimal policy chosen is closer to that party's point of view; i.e., $\theta$ is reduced. Therefore, each party benefits from an increase in its own popularity. In fact, it is easy to check that

$$
\frac{\partial Z^{D^{*}}}{\partial P}=\frac{\partial Z^{D^{*}}}{\partial \theta} \frac{\partial \theta^{*}}{\partial P}<0
$$

and

$$
\frac{\partial Z^{R^{*}}}{\partial P}=\frac{\partial Z^{R^{*}}}{\partial \theta} \frac{\partial \theta^{*}}{\partial P}>0,
$$

where $Z^{D^{*}}$ and $Z^{R^{*}}$ are the costs for the two parties evaluated at the Nash bargaining solution on the efficient frontier. If $P$ tends to either of the extreme values of zero or one, $\theta^{*}$ also tends to its extreme values of zero or infinity, while if the parties are equally likely to be elected, their points of view are weighted equally.

The basic qualitative features of the Nash bargaining solution, namely that the selected point of the efficient frontier is more favorable to the party that is more likely to be elected, would apply also to alternative ways of choosing a point on the efficient frontier. These features derive from the fact that a change in $P$ affects the costs of the two parties at the "disagreement point." Any solution concept used to select a point on the efficient frontier would be sensitive to such a change: in particular, an increase in the welfare of a player at the disagreement point would, ceteris paribus, imply that the selected point on the efficient frontier would be more favorable to that player. ${ }^{12}$ In summary, the common sense captured by these results is that the more popular party can impose upon the other an agreement close to its point of view.

11. Alesina [1986] shows that in a model in which the probability of electoral outcome is endogenous, "popularity" of a party has to be interpreted in this context as the likelihood of electing this party, if the noncooperative policies are followed.

12. This would be the case if, for example, the solution proposed by KalaiSmorodinsky [1975] or an asymmetric Nash-bargaining solution were chosen. 


\section{Sustainability of THE EFficient FrontieR}

Not all points on the efficient frontier are sustainable as a subgame perfect equilibrium, i.e., as a time-consistent policy, for any value of $P$ and $q$ unless binding commitments are available. Once elected, each party has an incentive to break the cooperation with the other party and play a policy advantageous to its own constituency in the short run. Suppose that before an election the parties announce that they would follow the optimal cooperative policy; i.e., $\Pi^{D}=\Pi^{R}=c /\left[1+\theta^{*}(P)\right]$. If this announcement is believed by the public, then $\Pi^{e}=\Pi^{D}=\Pi^{R}$. After the election, the victorious party has an incentive to deviate from the announced policy and minimize its short-run costs by playing its one-shot Nash strategy. In particular, party $D$ 's incentive arises from two sources: the desire to determine unexpected inflation, therefore "cheating" on the wage-setters' expectations, and the desire to break the implicit agreement with the competing party to cooperate on a "middle policy." Party $R$ faces only the second incentive, since it does not attribute any value to unexpected inflation. Without any form of enforcement, the only possible equilibrium would be the suboptimal one-shot Nash described in Proposition 1. Thus, binding commitment of both parties to the optimal policy would force them to stick to a rule that makes them both better off, even if in the short run both parties would want to follow a different policy more favorable to their own constituencies.

However, even if absolutely binding commitments are unavailable, reputational considerations are taken into account if the players understand that their interaction is repeated over time and thus that today's action influences the actions tomorrow of the other players. The solution concept adopted for the repeated game is that proposed by Friedman [1971]: the crucial assumption in this solution concept is that if one player deviates from cooperation, the other players will no longer believe that player's announcements and will play noncooperatively; i.e., they play the "one-shot" Nash strategy. ${ }^{13}$ Thus, there is a reversion to the noncooperative outcome if a player cheats. Note that the costs of a deviation from cooperation of, say, party $D$, arise from two sources: the reversion of party $R$ to the noncooperative policy and the reversion of the expectations of the public to the noncooperative equilibrium.

13. Abreu [1983] has shown that harsher punishments than the reversion to the one-shot Nash can be credibly threatened. Rogoff [1987] has applied these more complex strategies to a monetary policy game. Here we restrict our attention to the reversion to the one-shot Nash. 
The length of the reversion to the noncooperative outcome, i.e., the "punishment period," is somewhat arbitrary in this type of game. Since the threat of a reversion to Nash is always credible, the "best" equilibrium can be sustained if the length of the punishment period is infinite. This assumption is made here, with no loss of generality. It can be shown easily that the length of the punishment and the value of the discount factor are completely isomorphic. The following result can then be established.

Proposition 4. For any given $\theta$, the conditions that have to be satisfied to make the rules $\Pi^{D}=\Pi^{R}=c /(1+\theta)$ sustainable as a subgame perfect equilibrium are

$$
\begin{gathered}
\left(\frac{c}{1+\theta}\right)^{2}-\frac{2 b c}{1+\theta}(1-q)-\frac{2 c^{2}}{1+\theta} \\
+(b+c)^{2}(1-q-P q)+2 P q c(b+c) \leq 0 ; \\
\left(\frac{c}{1+\theta}\right)^{2}-P q(b+c)^{2} \leq 0 .
\end{gathered}
$$

Proof. Equation (22) is the condition of subgame perfection for party $D$. It can be obtained as follows. If party $D$ is elected, it faces the temptation $\left(T^{D}\right)$ of playing $\Pi^{D}=(b+c)$ instead of the cooperative policy $\Pi=c /(1+\theta)$. Thus,

$$
\begin{aligned}
T^{D}=\frac{1}{2}\left(\frac{c}{1+\theta}\right)^{2}-\frac{c^{2}}{1+\theta}- & \frac{1}{2}(b+c)^{2} \\
& +b\left(b+c-\frac{c}{1+\theta}\right)+c(b+c) .
\end{aligned}
$$

If party $D$ plays $(b+c)$, it knows that in the future the one-shot Nash equilibrium will prevail instead of the rule $c /(1+\theta)$. The enforcement $\left(E^{D}\right)$ is given by the difference between the cost of the Nash equilibrium and the cost of the cooperative rule. Therefore,

$$
E^{D}=\frac{q}{1-q}\left[P \frac{1}{2}(b+c)^{2}-P c(b+c)-\frac{1}{2}\left[\frac{c}{1+\theta}\right]^{2}+\frac{c^{2}}{1+\theta}\right] .
$$

Equation (22) follows from a simple manipulation of (24) and (25). Analogous argument applied to party $R$ leads to (23). Note that to obtain these conditions we have considered the private agents acting rationally. They know that if a cheating episode occurred, the outcome of the game would revert to a one-shot Nash forever; 
therefore, they would expect this outcome forever in the future if they observed a cheating episode.

Q.E.D.

Inspection of (22) and (23) confirms that the less the two parties discount the future, the easier it is to sustain the cooperative rule. Furthermore, it is easy to verify that the lower is $\theta$, the more difficult it is to satisfy the sustainability condition for party $R$, and vice versa. The party whose interests are weighted less would find it less attractive to cooperate because the cooperative rule chosen is farther away from its point of view. Given Proposition 3, one might suspect that it should be easier to sustain full cooperation when $P$ is relatively close to $1 / 2$. In fact, if $P$ is close to any of its extremes, so is $t$, and one of the two parties would lose interest in playing cooperatively. Thus, in an unbalanced system in which one party has little chance of ever being elected, cooperation would be harder to sustain because that party has a strong incentive to deviate from cooperation and play its own preferred policy when elected.

In order to quantify these considerations, one would need a closed form for the Nash bargaining solution $\left(\theta^{*}\right)$. Lacking this, an approximation can be considered as an example:

$$
\theta^{*} \simeq(1-P) / P \text {. }
$$

It is easy to verify that this expression satisfies all the characteristics described in Proposition 3 for the Nash bargaining solution. This approximation is particularly precise for $P$ close to $1 / 2$. Furthermore, it can be verified that the qualitative features of the results that follow do not change if different approximations are used. Substituting (26) into (22) and (23) yields the following constraints of subgame perfection:

$$
\begin{gathered}
q \geq \frac{P c^{2}}{(b+c)^{2}} \quad(\text { party } R) ; \\
q \geq \frac{[c(1-P)+b]^{2}}{b^{2}(1+P)+\left(c^{2}+2 b c\right)(1-P)} \quad(\text { party } D) .
\end{gathered}
$$

These conditions have an intuitive interpretation. Suppose for a moment that $b=0$. In this case, the game would be symmetric because party $D$ would not face the additional incentive to cheat on private agents' expectations that party $R$ does not have. Conditions (27) and (28) would reduce to

$$
q \geq P
$$




$$
q \geq 1-P .
$$

In Figure II the area $A B C$ is the one in which both (29) and (30) are satisfied, and full cooperation is attainable. It is easiest to sustain full cooperation when $P=1 / 2$; i.e., when two parties are of equal popularity. With $b \neq 0$, the system loses its symmetry because of the additional incentive to deviate from announcements that only party $D$ has. Figure III shows that because of this additional temptation the area in which full cooperation is sustainable shrinks, and it is easiest to sustain cooperation at $\bar{P}>1 / 2$. Therefore, in a system in which there is a very weak and a very strong party, there is less incentive for the two parties to cooperate than in a more balanced system. This effect is particularly strong if the weaker party is also the party that benefits more from policy surprises.

\section{The Best Credible Policies}

Full cooperation may not be sustainable if the parties discount the future heavily. There are several reasons why $q$ may be low. Besides the usual ones, an additional reason stems from the solution concept used for this game and the length of the punishment period chosen. For example, one party may assign a positive probability to the event that the leadership of the opponent party may change in the future and that the new leadership will not carry out the threats

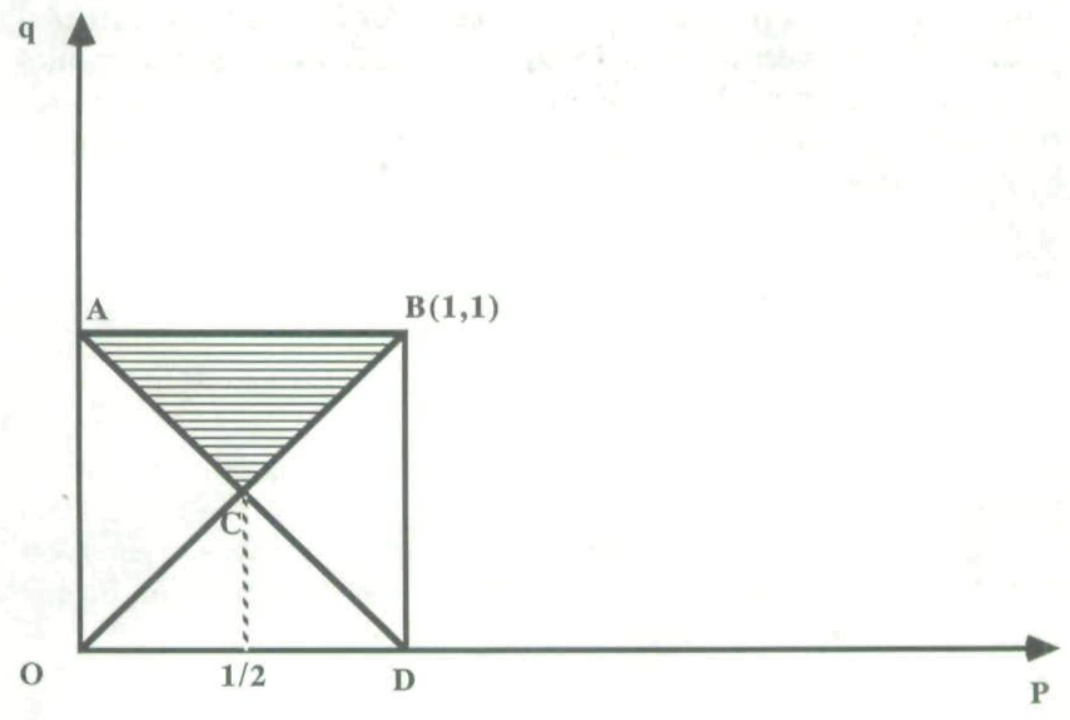

Figure II 


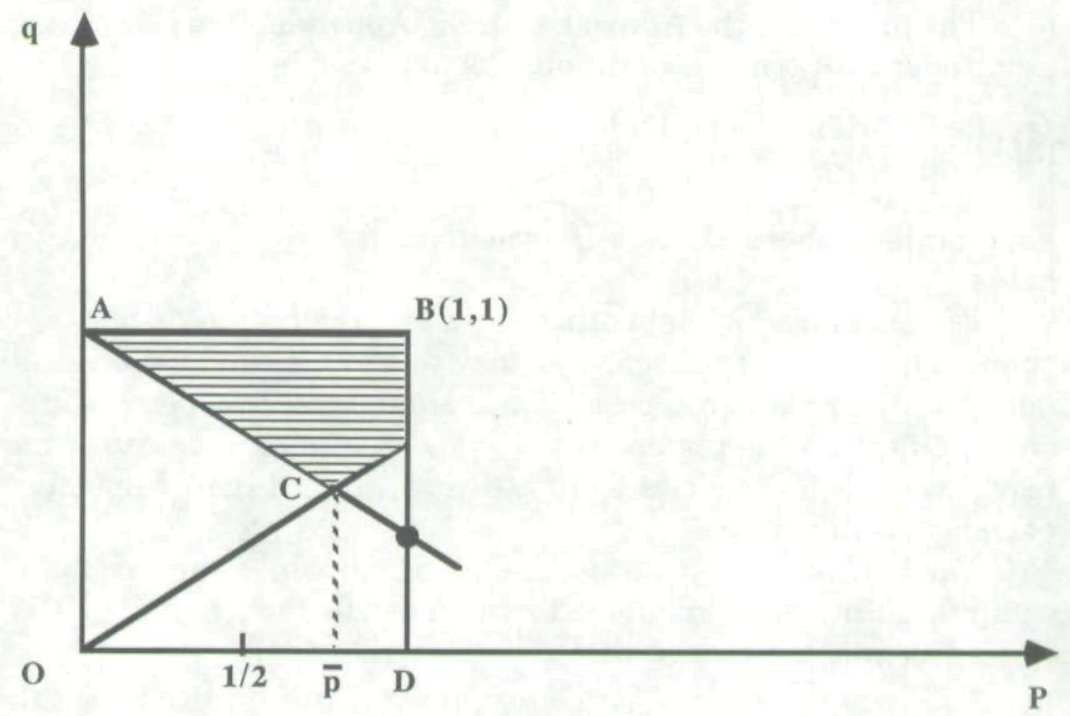

Figure III

of the old. This could be modeled by assigning a positive probability to a finite length of the period in which the system reverts to the one-shot Nash if a cheating episode occurs; in this game this is qualitatively equivalent to assuming a low discount factor.

Let us continue to assume that the parties use the Nash solution to solve the bargaining problem (i.e., to choose $\theta$ ). The best credible rules can be found by solving problem (16) under the two subgame perfection constraints. These two constraints assure that the policies followed by the two parties are credible, i.e., timeconsistent. They can be obtained by imposing that any pair of policies $\left(\Pi^{D}, \Pi^{R}\right)$ has to satisfy the condition that the temptation to deviate from them is not greater than the enforcement associated with this deviation. These constraints can be written following the same steps used in the proof of Proposition 4. The following result characterizes this solution.

Proposition 5. If the Nash bargaining solution on the efficient frontier, $\Pi^{D}=\Pi^{R}=\Pi^{e}=c /\left[1+\theta^{*}(P)\right]$, cannot be credibly announced by the two parties, then if $q>0$, the best credible policies $\left(\bar{\Pi}^{D}, \bar{\Pi}^{R}\right)$ satisfy the following condition:

$b+c>\bar{\Pi}^{D}(q, P, b, c)>c /\left(1+\theta^{*}(P)\right)>\bar{\Pi}^{R}(q, P, b, c)>0$.

If and only if $q=0$, the best credible policies are

$$
\bar{\Pi}^{D}=b+c ; \quad \bar{\Pi}^{R}=0 .
$$


The proof is in the Appendix. In the Appendix it is also shown that under very general conditions the following holds:

$$
\frac{\partial \bar{\Pi}^{D}}{\partial q}>0, \frac{\partial \bar{\Pi}^{R}}{\partial q}<0 \quad \text { for any value of } q .
$$

Furthermore, there exists a $\bar{q}$ such that, for $q<\bar{q}$, (31) always holds.

Proposition 5 highlights that if $q$ is low, the parties do not care about the future very much, and they follow policies that tend to minimize their short-run costs. Their announcements become less credible both to the opponent party and the private agents. As a result, the parties' policies tend to diverge toward their respective one-shot Nash policies.

Thus, if full cooperation is not sustainable, the economy exhibits output and inflation fluctuations. In fact, if party $D$ is elected at time $t$, it follows that

$$
y_{t}=\gamma(1-P)\left(\bar{\Pi}^{D}-\bar{\Pi}^{R}\right),
$$

and if party $R$ is elected,

$$
y_{t}=-\gamma P\left(\bar{\Pi}^{D}-\bar{\Pi}^{R}\right) .
$$

Since $\bar{\Pi}^{D}>\bar{\Pi}^{R}$, there is a recession with low inflation with an $R$ administration, and an expansion above the natural rate with a $D$ administration. Furthermore, the variances of output and of inflation are decreasing functions of the discount factor and increasing functions of $b$ and $c$, i.e., the distance between the two parties' points of view.

In this type of game there is no assurance that the players would indeed pick the "best" of the infinitely many subgame perfect Nash equilibria of the game. The multiplicity of equilibria in this type of game is a well-documented disturbing fact: Rogoff [1987] investigates this issue in the context of monetary policy games. However, the proof of Proposition 5 highlights that if the policies $\Pi^{D}=\Pi^{R}=c /(1+\theta)$ are not sustainable, all the subgame perfect equilibria satisfy the condition that $\Pi^{D}>\Pi^{R}$. Thus, the positive implications of the paper for the business cycle do not require that the parties pick the best credible policies but only that they pick any credible policy when the first best is not sustainable.

\section{EXTENSIONS}

The extension to the case of multiperiod administrations is conceptually quite simple. The one-shot Nash equilibrium for this 
case has been already characterized in Proposition 1. It is easy to verify that the efficient frontier is the same for a multiperiod administration; i.e., $\Pi^{D}=\Pi^{R}=c /(1+\theta)$ in each period. However, the conditions of sustainability of the efficient frontier as a perfect equilibrium are not the same in different periods of an administration. Consider, for example, party $R$. Even though its temptation to cheat is the same in every period, the enforcement is a function of the distance in time from the following elections. During the $j$ th year of a $R$ administration, the enforcement $\left(E_{j}^{R}\right)$ is, in fact,

$$
E_{j}^{R}=\left[q^{(N+1-j)} /(1-q)\right]\left(\hat{z}^{R}-z^{R^{*}}\right) .
$$

Clearly, the farther away in time is the next election, the farther in the future is the beginning of the "punishment" if a deviation from announcements occurs; therefore, the lower is the enforcement. The same considerations would apply to party $D$. The only difference for party $D$ is that part of the "punishment" would occur immediately after a cheating episode due to the reversion of expectations of the private agents to the Nash outcome. However, the "punishment" coming from party $R$ 's reversion to the one-shot Nash would not occur until the following election. Both parties have then a stronger incentive to deviate from announcements of cooperative agreements at the beginning of the terms of office; thus following Proposition 5, it can be argued that the farther in the future are the following elections the more different are the policies of the two parties. Note, however, that policy surprises creating deviations of output growth from its natural level can occur only in the first period of an administration.

Thus far we have emphasized the strategic interaction of the two parties. This paper can incorporate as a particular case the reputational mechanism involving only the public's expectations, as in Barro-Gordon [1983]. Consider, for example, the case in which party $R$ always sets $\Pi^{R}=0$ because, for example, it completely discounts the future and cares only about the inflation rate when in office. In this situation party $D$ would not necessarily follow the policy $\Pi^{D}=b+c$, i.e., the one-shot Nash policy. By engaging in a reputational game with the public, party $D$ can sustain a policy $\tilde{\Pi}^{D}$ that satisfies the following:

$$
c \leq \tilde{\Pi}^{D}<b+c .
$$

Needless to say, party $D$ would never find it in its interest to follow a policy $\Pi^{D}<c$, since $c$ is the optimal inflation rate for this party and party $R$ is not willing to cooperate to an intermediate policy. A policy such as $\tilde{\Pi}^{D}$ in (35) could be enforced by means of trigger 
strategies involving the public's expectations. If party $D$ announces $\tilde{\Pi}^{D}$ and then deviates, following $\Pi^{D}=b+c$, the public would expect this party to follow $b+c$ in the future. Thus, some algebra establishes that the enforcement associated with a deviation from the rule $\tilde{\Pi}^{D}$ in the $J$ th period of an $N$ period's administration is

$$
\begin{aligned}
E^{D}=\frac{q\left(1-q^{N-J}\right)}{1-q}\left[\frac{1}{2} b^{2}-\frac{1}{2}(\tilde{\Pi}-c)^{2}\right] & \\
& +\frac{P q^{N+1-J}}{1-q}\left[\frac{1}{2} b^{2}-\frac{1}{2}(\tilde{\Pi}-c)^{2}\right] .
\end{aligned}
$$

The first term in (36) represents the costs of the reversion of expectation to $b+c$ during the remaining $(N-J)$ period(s) of the current administration. The second term represents the effect of the reversion of expectations after the end of the current term of office. Using (36), it is easy to verify that the best credible policy for party $D$ satisfies (35). If $q$ is sufficiently close to 1 , the policy $\Pi^{D}=c$ is credible. ${ }^{14}$

\section{CONCLUSIONS}

This paper characterizes an economic cycle connected to the political cycle. The predictions of the model are quite different from those of the political business cycle literature which implies that one should observe recessions at the beginning of any type of administration and inflationary expansions toward the end. The prediction of this paper is that in the United States one should instead observe recessions at the beginning of Republican administrations, as compared with output growth above trend and higher inflation at the beginning of Democratic administrations. In the second part of both types of administrations, output growth should be about the same, with higher inflation during a Democratic administration. Alesina-Sachs [forthcoming] find that these empirical implications are not rejected by United States postWorld War II data.

14. It is easy to verify that for $P=1$, i.e., the case of a single party, (36) is equivalent to the Enforcement of Barro-Gordon [1983]; the only difference is that Barro and Gordon consider a punishment of one period, while here the punishment period is infinite. The interaction of the punishment coming from the public and from the opponent party is also explored in a different context by Rogoff-Sibert [1986]. 
The results presented in this paper do not rely on irrational expectations formation or irrational voting behavior. Although voting is exogenous in this paper, Alesina [1986] shows that all the results of the present paper can be generalized in a model with rational and perfectly informed voters. The assumption adopted about voting has emphasized the contrast between this paper and the traditional "political business cycle" literature; Rogoff-Sibert [1985] have shown that a cycle on inflation similar to that of Nordhaus [1975] can be generated in a model with rational but imperfectly informed voters. It should be stressed that the present paper and that of Rogoff and Sibert are in many respects complementary, and in principle future research could develop both insights into a unified framework.

The equilibrium with cycles in this model has been shown to be suboptimal. If the parties agree to follow an identical policy, the cycle is avoided. There would be no fluctuations in output, and inflation and both constituencies would be better off. This policy has been characterized formally as the result of a bargaining process between the two parties, in which the more popular party can impose an agreement closer to its point of view. A commitment to the cooperative rule is beneficial because it binds the two parties to a policy that improves welfare for both of them in the long run. Even if binding commitments are not available, reputational forces due to the repeated interaction of the two parties and the public can improve upon the discretionary equilibrium by reducing the magnitude of the fluctuations of inflation and output.

The central ideas of this paper are quite general and go well beyond the specific example on inflation and output. This paper has shown how the repeated interaction of political parties may reduce the excess volatility of policies. The reduction of volatility is particularly beneficial in all the cases in which frequent and drastic switches of policies associated with changes in administrations are costly. ${ }^{15}$ In all these cases reputational mechanisms such as those described in this paper create an incentive for the two parties to converge to more similar policies and create less disruption when a change in administration occurs.

15. A referee has suggested the following example. Suppose that the government has complete freedom of firing civil service employees. Every time the incumbent loses the election, the winner may want to fire everybody and appoint different people. This may create a suboptimally high level of turnover. The repeated interaction of the two parties may lead to an equilibrium in which highly competent party $D$-affiliated employees are kept in office when party $R$ wins and vice versa. 


\section{APPENDIX}

\section{Proof of Proposition 3}

The Nash bargaining solution on the efficient frontier is found by solving the following problem (time subscripts are dropped for convenience):

$$
\min _{z^{D}, z^{R}}\left(z^{D}-A^{D}\right)\left(z^{R}-A^{R}\right)
$$

such that

$$
\begin{gathered}
z^{D} \leq z^{R}-c \sqrt{2 z^{R}}, \\
z^{D}-A^{D} \leq 0, \\
z^{R}-A^{R} \leq 0 .
\end{gathered}
$$

where $\left(A^{D}, A^{R}\right)$ is the disagreement point, i.e., the costs for the two parties if the agreement is not reached. If an agreement is not reached, the two parties would follow their individual mostpreferred policies. Therefore, party $D$ would choose $\Pi^{D}=c$, and party $R \Pi^{R}=0$. It follows that

$$
\begin{gathered}
A^{D}=-\frac{1}{2} P c^{2} ; \\
A^{R}=\frac{1}{2} P c^{2} .
\end{gathered}
$$

Alternatively, one might choose as the disagreement point the "one-shot" Nash (i.e., $\Pi^{D}=b+c, \Pi^{R}=0$ ). The results would not qualitatively change. Furthermore, it is more reasonable to assume that party $D$ would follow its most preferred policy if an agreement is not reached, rather than a suboptimal policy. (The policy $\Pi^{D}=c$ is sustainable for party $D$, if $\Pi^{R}=0$, as shown in Section VII if $q$ is sufficiently close to one.) Let us redefine for convenience

$$
\begin{aligned}
& y \equiv-\left(z^{D}-A^{D}\right)=-\left[z^{D}+\frac{1}{2} P c^{2}\right] ; \\
& x \equiv-\left(z^{R}-A^{R}\right)=-\left[z^{R}-\frac{1}{2} P c^{2}\right] .
\end{aligned}
$$

The problem then can be rewritten as follows:

$$
\max _{x, y} \Phi=x y,
$$

such that

$$
\begin{gathered}
y=x-P c^{2}+c \sqrt{P c^{2}-2 x}, \\
y \geq 0, \\
x \geq 0 .
\end{gathered}
$$


Equation (A.10) has been rewritten as an equality because the solution must lie on the frontier. Substituting (A.10) into (A.9), the first-order condition of the problem implies that an interior solution satisfies the following:

$$
\frac{\partial \Phi}{\partial x}=2 x-P c^{2}+c \sqrt{P c^{2}-2 x}-\frac{c x}{\sqrt{P c^{2}-2 x}}=0 .
$$

On the frontier the costs for party $D$ in each period are

$$
z^{D}=\frac{1}{2} \frac{c^{2}}{(1+\theta)^{2}}-\frac{c^{2}}{1+\theta} .
$$

Using (A.5), (A.13), and (A.14), we obtain

$$
\left(P c^{2}-2 x\right)=c /(1+\theta)^{2} .
$$

Substituting into (A.10) and rearranging yields

$$
P=(3 \theta+1) /(1+\theta)^{3} .
$$

From (A.16) it is easy to verify that $\theta^{*}(P)$ is a decreasing function of $P$ for $\theta>0$. Suppose that $P=0$. (A.8) and (A.12) imply that

$$
c^{2} /(1+\theta)^{2} \leq 0 .
$$

(A.17) can be satisfied only for $\theta \rightarrow \infty$. Suppose that $P=1$. (A.7) and (A.11) imply that

$$
\frac{1}{2} \frac{c^{2}}{(1+\theta)^{2}}-\frac{c^{2}}{1+\theta}+\frac{1}{2} c^{2} \leq 0 .
$$

(A.18) is satisfied if and only if $\theta=0$. Finally, it is easy to check that if $P=1 / 2$ then $\theta^{*}=1$, using (A.16).

$$
\text { Q.E.D. }
$$

\section{Proof of Proposition 5}

After some algebra, it can be shown that the problem to be solved is the following:

(A.19) $\min _{\Pi^{D}, \Pi^{R}}\left[P\left[\Pi^{D}-\frac{c}{1+\theta}\right]^{2}+(1-P)\left[\Pi^{R}-\frac{c}{1+\theta}\right]^{2}-\frac{c^{2}}{(1+\theta)^{2}}\right]$,

such that

$$
\Pi^{R^{2}}+\frac{P q}{1-q} \Pi^{D^{2}}-\frac{P q}{1-P q}(b+c)^{2} \leq 0
$$




$$
\text { (A.21) } \begin{aligned}
& (1-q+P q)\left(\Pi^{D}-\frac{(b+c)(1-q)+q P c}{1-q+q P}\right)^{2} \\
& +q(1-P)\left(\Pi^{R}-c\right)^{2}-\frac{[(b+c)(1-q)+q P c]^{2}}{1-q+P q} \\
& \quad+(b+c)[(b+c)(1-q-q P)+2 P q c]-q(1-P) c^{2} \leq 0 .
\end{aligned}
$$

The conditions of individual rationality have also to be satisfied at the solution. The constraint of subgame perfection for party $R$ (A.20) is an ellipse centered on the origin (see Figure IV). The intersections with the axes are
(A.22)

$$
\Pi^{D}= \pm(b+c),
$$

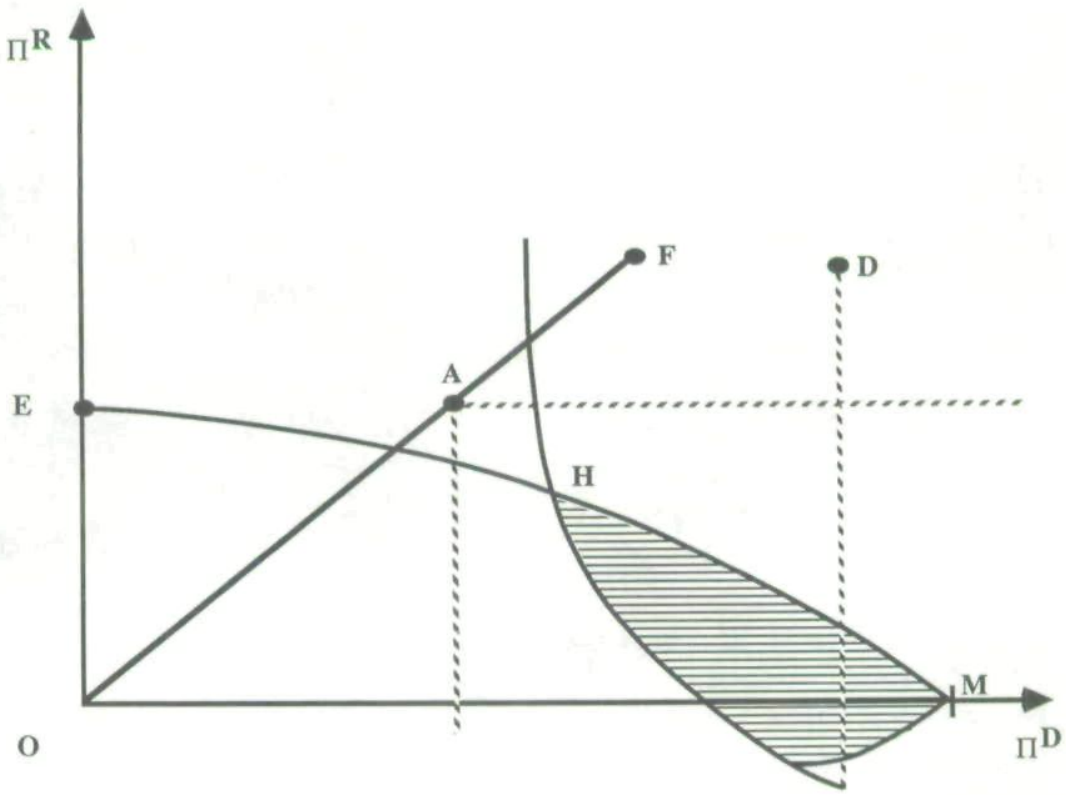

FigURE IV

$$
\begin{aligned}
D: \begin{cases}\Pi^{R}=c & F: \Pi^{R}=\Pi^{D}=c \\
\Pi^{D}=\frac{(b+c)(1-q)+q P c}{1-q+P q} & A: \Pi^{R}=\Pi^{D}=\frac{c}{1+\theta^{*}}\end{cases} \\
E:\left\{\begin{array} { l } 
{ \Pi ^ { D } = 0 } \\
{ \Pi ^ { R } = \sqrt { \frac { P q } { 1 - P q } } ( b + c ) }
\end{array} M \left\{\begin{array}{l}
\Pi^{R}=0 \\
\Pi^{D}=(b+c)
\end{array}\right.\right.
\end{aligned}
$$




$$
\Pi^{R}= \pm \frac{\sqrt{P q}}{1-P q}(b+c) .
$$

The constraint for party $D$ (A.22) is an ellipse centered at

$$
\left[\begin{array}{l}
\Pi^{R}=c, \\
\Pi^{D}=\frac{(b+c)(-q)+q P c}{1-q+q P} .
\end{array}\right.
$$

Note that

$$
c<\frac{(b+c)(1-q)+q P c}{1-q+q P}<b+c .
$$

Suppose that the Nash bargaining solution on the efficient frontier lies outside both feasible sets (point $A$ in Figure IV). The solution of the problem is in the dashed area. By construction this proves that, at the solution,

$$
\Pi^{D}>c /\left(1+\theta^{*}\right)>\Pi^{R} .
$$

From (A.19) it follows that a pair of policies $\left(\tilde{\Pi}^{R}, \tilde{\Pi}^{D}\right)$ with $\tilde{\Pi}^{R}<0$ is clearly inferior to the pair $\left(0, \tilde{\Pi}^{D}\right)$ for $\theta>0$. By construction, if the former pair is sustainable, so is the latter. By construction, a pair of policies $\left(\tilde{\Pi}^{R}, \tilde{\Pi}^{D}\right)$ with $\tilde{\Pi}^{D}>b+c$ is not sustainable for party $R$. Therefore, the first part of the proposition follows. Suppose that $q=0$. Then the two constraints of subgame perfection, (A.21) and (A.22), become

$$
\begin{gathered}
\Pi^{R^{2}} \leq 0, \\
{\left[\Pi^{D}-(b+c)\right]^{2} \leq 0 .}
\end{gathered}
$$

From (A.27) and (A.28) it follows that if $q=0$, the only subgame perfect equilibrium is the one-shot Nash. It is easy to verify that, as long as $q>0$, a dashed area such as that of Figure Ia exists, and some cooperation is sustainable, i.e., $\Pi^{D}<b+c$ and $\Pi^{R}>0$ at the solution.

Let us now consider a fall in $q$. The two feasible sets shrink. In fact, any combination of strategies sustainable at a lower $q$ has to be sustainable at a higher $q$. It is easy to verify algebraically that this is in fact the case. Graphically the shift is described in Figure V, where the two feasible sets at the lower value of $q$ are represented with dashed lines. From (A.24) it follows that the center of party D's ellipses moves to the right along the horizontal line $\Pi^{R}=c$, when $q$ 


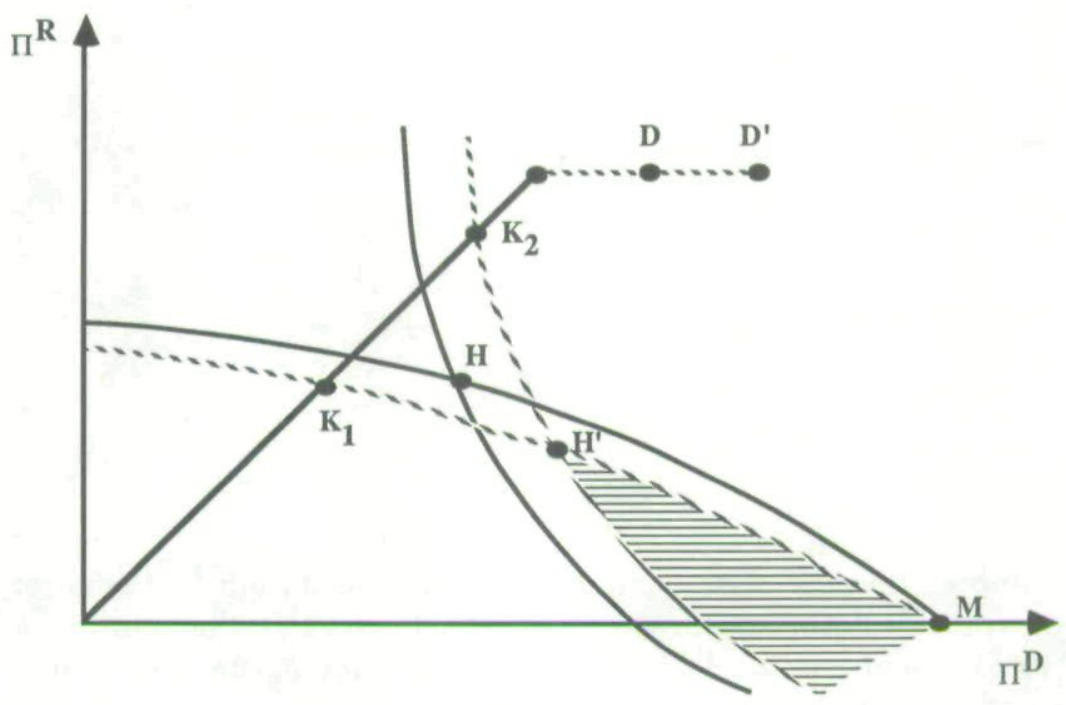

Figure V

falls. Note that if a change in $q$ does not change the value of $\theta^{*}$ at the solution, the following holds (at the solution):

$$
\frac{\partial \Pi^{D}}{\partial q}>0, \quad \frac{\partial \Pi^{R}}{\partial q}<0 .
$$

Conditions (A.29) hold in general if the change in $\theta$ at the solution associated with a change in $q$ is not too big. Furthermore, as long as the chosen $\theta$ is such that $c /(1+\theta)$ lies between $K_{1}$ and $K_{2}$ in Figure V, (A.29) holds. In fact, in this case the solution shifts from $H$ to $H^{1}$, thus satisfying (A.29). Thus, by construction, it follows immediately that there exists a value of $q$, say $\bar{q}$, such that, for $q \leq \bar{q}$, (A.29) always hold.

Q.E.D.

CARNegie Mellon University

\section{REFERENCES}

Abreu, Dilip, "Infinitely Repeated Game with Discounting: A General Theory and Application to Oligopoly," Ph.D. Thesis, Princeton University, 1983.

Alesina, Alberto, "Rules, Discretion and Reputation in a Two-Party System," mimeo, March 1985.

, "Credibility and Policy Convergence in a Two-Party System with Rational Voters," mimeo, October 1986. 
and Jeffrey Sachs, "Political Parties and the Business Cycle in the United States, 1948-1984," Journal of Money, Credit and Banking, forthcoming.

— , and Guido Tabellini, "Rules and Discretion with Non-coordinated Monetary and Fiscal Policy," Economic Inquiry, forthcoming.

Barro, Robert, and David Gordon, "Rules, Discretion and Reputation in a Model of Monetary Policy," Journal of Monetary Economics, XII (July 1983), 101-22.

Beck, Nathaniel, "Parties, Administrations and American Macroeconomic Outcomes," American Political Science Review, XXVI (March 1982), 83-93.

_ - "Domestic Political Sources of American Monetary Policy: 1955-82," Journal of Politics, XLVI (August 1984), 786-815.

Blanchard, Olivier, "Credibility, Disinflation and Gradualism," Economics Letters, XVII (1985), 211-17.

Calvert, Randall, "Robustness of the Multidimensional Voting Model Candidate Motivations, Uncertainty and Convergence," American Journal of Political Science, XXIX (February 1985), 69-95.

Cukierman, Alex, "Central Bank Behavior and Credibility: Some Recent Theoretical Developments," Federal Reserve Bank of St. Louis Review, LXVIII (May 1986), 5-17.

Downs, Anthony, An Economic Theory of Democracy (New York, NY: Harper, 1957).

Driffil, John, "Macroeconomic Stabilization Policy and Trade Union Behavior as a Repeated Game," Institute for International Economic Studies, Stockholm, Seminar Paper No. 301, January 1985.

Fischer, Stanley, "Long Term Contracts, Rational Expectations and the Optimal Money Supply Rule," Journal of Political Economy, LXXXV (February 1977), 191-206.

- "Time Consistent Monetary and Fiscal Policies: A Survey," mimeo, January 1986.

Friedman, James, "A Non-Cooperative Equilibrium for Supergames," Review of Economic Studies, XXXVIII (January 1971), 1-12.

Golden, David, and James Poterba, "The Price of Popularity: The Political Business Cycle Reexamined," American Journal of Political Science, XXIV (November 1980), 696-714.

Havrilesky, Thomas, "Monetary Policy Signaling from the Administration to the Federal Reserve," mimeo, January 1986.

- "A Partisan Theory of Fiscal and Monetary Regimes," Journal of Money Credit and Banking, forthcoming.

Hibbs, Douglas, "Political Parties and Macroeconomic Policy," American Political Science Review, LXXI (December 1977), 1467-87.

-, The American Political Economy: Electoral Policy and Macroeconomics in Contemporary America (Cambridge MA: Harvard University Press, forthcoming).

Kalai, Ehud, and Meir Smorodinsky, “Other Solutions to Nash's Bargaining Problem,” Econometrica, XLIII (May 1975), 513-18.

Kydland, Finn, and Edward Prescott, "Rules Rather than Discretion: The Inconsistency of Optimal Plans," Journal of Political Economy, LXXXV (June 1977), 473-91.

McCallum, Bennett, "The Political Business Cycle: An Empirical Test," Southern Economic Journal, XLIV (January 1978), 504-15.

McRae, Duncan, "A Political Model of the Business Cycle," Journal of Political Economy, LXXXV (April 1977), 239-64.

Minford, Patrick, and David Peel, "Political Theory of the Business Cycle," European Economic Review, XVII (February 1982), 253-70.

Nordhaus, William, "The Political Business Cycle," Review of Economic Studies, XLII (April 1975), 169-90.

Poole, Keith, and Howard Rosenthal, "The Dynamics of Interest Groups Evaluations of Congress," GSIA, Carnegie Mellon University working paper No. 3-86-87, 1986.

Rogoff, Kenneth, "The Optimal Degree of Commitment to an Intermediate Monetary Target," this Journal, C (November 1985), 1169-90.

_- "Reputational Constraint on Monetary Policy," in Carnegie-Rochester Conference Series on Public Policy, XXVI (Spring 1987), pp. 141-81.

- and Anne Sibert, "Equilibrium Political Business Cycles," National Bureau of Economic Research, working paper No. 1838, February 1986. 
Tabellini, Guido, "Centralized Wage Setting and Monetary Policy in a Reputational Equilibrium," UCLA working paper No. 369, April 1985.

, and Vincenzo La Via, "Money, Deficit and Public Debt: An Empirical Investigation," mimeo, September 1986.

Taylor, John, "Aggregate Dynamics and Staggered Contracts," Journal of Political Economy, LXXXVII (February 1980), 1-23.

Weintraub, Robert, "Congressional Supervision of Monetary Policy," Journal of Monetary Economics, IV (1978), 341-62.

Wittman, Donald, "Candidates with Policy Preferences: A Dynamic Model," Journal of Economic Theory, XIV (February 1977), 180-89.

- "Candidate Motivation: A Synthesis of Alternatives," American Political Science Review, LXXVI (March 1983), 142-57. 
Copyright of Quarterly Journal of Economics is the property of MIT Press and its content may not be copied or emailed to multiple sites or posted to a listserv without the copyright holder's express written permission. However, users may print, download, or email articles for individual use. 